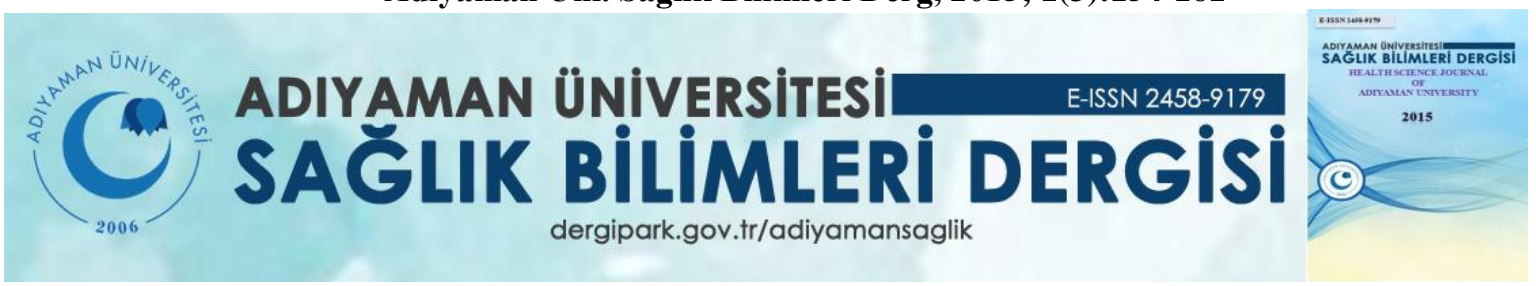

Olgu sunumu/ Case report

\title{
Sinüzit Sonucu Gelişen Pediatrik Subperiostal Orbital Apse: \\ Olgu Sunumu
}

\author{
Ali ŞİMŞEK ${ }^{1}$, Sedat DOĞAN ${ }^{2}$, Ali Asgar YETKİN ${ }^{1}$, Mübeccel BAĞDAŞ ${ }^{1}$ \\ ${ }^{1}$ Adiyaman Üniversitesi, Tıp Fakültesi, Göz Hastalıkları Anabilim Dalı, Adıyaman, \\ ${ }^{2}$ Adiyaman Üniversitesi, Eğitim ve Araştırma Hastanesi, Kulak Burun Boğaz Anabilim Dalı, Adıyaman,
}

ÖZ

Yedi yaşında bir erkek hasta sol göz kapağında üç gündür devam eden ağrı, şişlik ile kliniğimize başvurdu. Yapılan oftalmolojik muayenesinde sol üst göz kapağı hiperemik ve ödemliydi. İlave olarak hastanın göz hareketlerinde içe bakışta kısıtlılık, direkt ve indirekt 1şık refleksleri normal idi. En iyi düzeltilmiş görme keskinliği 8/10. Hastanın bilgisayarlı tomografisinde subperiostal orbital abse izlendi ve sistemik antibiyotik tedavisi başlandi. Takiplerinde propitozisin artması ve görme keskinliğinin 5/10 a kadar düşmesi üzerine kulak burun boğaz kliniği ile görüşülerek endoskopik drenaj planlandı. Cerrahinin birinci gününde görme keskinliği 8/10 çıktı, kapaktaki hiperemi ve ödemi azaldı. Onuncu gün kontrolünde görme keskinliği 10/10,göz kapağ1 normal ve göz hareketlerinin her yöne serbest olduğu görüldü. Akut rinosinüzit sekonder orbital enfeksiyonların önemli sebeplerinden birisidir. Akut rinosinüzitin mortalitesi yüksek olan orbital komplikasyonları özellikle çocuklarda görülür.

Anahtar kelimeler; Subperiostal abse, sinüzit, endoskopik drenaj

Yazışmadan Sorumlu Yazar

Ali ŞİMŞEK

Adıyaman Üniversitesi, Eğitim ve Araştırma

Hastanesi, Göz Hastalıkları Anabilim Dalı, Adıyaman.

Tel : +90 05302227760

Email: alisimsek1980@gmail.com
Geliş Tarihi: $\quad$ 14.11.2017

Kabul Tarihi: $\quad$ 24.11.2017 


\section{Pediatric Subperiostal Orbital Abscess Due to Sinusitis: A Case Report}

\section{Summary}

A seven-year-old male patient applied to our clinic with pain and swelling on his left eyelid for three days. On the ophthalmologic examination, his left upper eyelid had hyperemic and edematous. Additionally, his had restriction in inside view in the left, and eye direct, and indirect light reflexes were normal. His best corrected visual acuity was 8/10. Subperiosteal orbital abscess was observed in the computerized tomography of the patient and systemic antibiotic treatment was started. Because of increased proptosis and decrease in visual acuity of up to $5 / 10$ in follow-up, endoscopic drainage was planned by talking with otorhinolaryngologist. On the first day after surgery, visual acuity was 8/10, hyperaemia, and edema decreased. At the tenth day after surgery, visual acuity was $10 / 10$, the eyelid was normal and eye movements were free in all directions. Acute rhinosinusitis is one of the major causes of secondary orbital infections. Orbital complications with high mortality of acute rhinosinusitis are seen especially in children.

Key Words: Subperiostal orbital abscess, sinusitis, endoscopic drainage 


\section{GİRIŞ}

Orbital enfeksiyonlar, orbita ve periorbital dokuların enfeksiyonudur (1). Paranazal sinüs enfeksiyonları başta olmak üzere delici yaralanma, göz kapağı enfeksiyonları, dakriyosistit, septisemi ve diş enfeksiyonları sonrasında gelişmektedir $(1,2)$. Orbita enfeksiyonları, orbital septumla ayrılmış anatomik alanlara göre, preseptal selülit, orbital selülit, subperiostal apse, orbital apse ve kavernöz sinüs trombozu olarak sinıflandırılır $(1,2$, 3). Çocukluk döneminde preseptal selülit, orbital selülit ve subperiostal apse, sinüzitin komplikasyonu olarak s1k görülmektedir (1, 3, 4). Sinüzit, burun ve paranazal sinüslerin enfeksiyonudur (6). Yumuşak doku infeksiyonları, orbital ve intrakraniyal komplikasyonları olmak üzere ciddi komplikasyonları vardır $(7,8,9,10,11)$. Orbital ve intrakraniyal komplikasyonları daha fazla görülür (4). Rinosinüzit komplikasyonlarının \%80'ni orbital komplikasyonlar oluşturur ve bu komplikasyonlar sinüslerden yayılım ile oluşur. Orbital komplikasyonlar orbita ve paranazal dokuların anatomik yakınlığından dolayı çocuklarda daha fazla görülür $(1,2,3,6,12)$. Zamanında tedavi edilmediği takdirde progresif bir şekilde ilerleyerek optik sinire uzanabilir, kavernöz sinüs tromboflebiti ve ciddi intrakraniyal komplikasyonlara sebep olabilir $(1,3,6,8,9,13)$. Orbital komplikasyonlar özellikle selülit veya abse şeklinde olur (3). En s1k görülen komplikasyon preseptal selülittir. Kapak hiperemik ve ödemlidir. kemozis ve propitozis yoktur ve göz hareketleri etkilenmemiştir (3). Propitozis ve kemozisin oluşması, göz hareketlerinin kısıtlanması ve görmenin azalması inflamasyonun orbitaya yayılımını orbital selülit oluştuğunu gösterir $(1,3,13)$. Orbital selülit tedavi edilmediği takdirde yayılarak intrakraniyal komplikasyonlara neden olur $(1,8,9)$. Başka bir komplikasyon ise subperiostal absedir. Subperiostal abse inflamasyonun orbita kemikleriyle periorbital dokular arasında yayılmasıdır $(1,3)$. Daha çok lamina papyracea ve periorbita arasında olur. Propitozis, kemozis göz hareket kısıtlılı̆gı vardır fakat lateral yöne bakabilir $(1,3,13)$. Orbital selülit ve orbital apseler, kavernöz sinüs trombozu, menenjit, 
subdural ampiyem ve beyin apsesine ilerleyebilir $(7,9) . \mathrm{Bu}$ nedenle erken tanı ve tedavi morbidite ve mortaliteyi kontrol altına almak için önemlidir. Komplikasyonların tedavisi konservatif, cerrahi veya kombine olabilir. Cerrahi teknik açık veya endoskopik olabilir $(3,6)$.

Bu sunumuzda kliniğimize propitozis ile başvurup subperiostal abse tanisi ile sistemik tedavi başladığımız ve tedaviye yanıt alamamız üzerine endoskopik cerrahi ile anlamlı iyileşme gördügümüz olgumuzu sunmayı planladık.

\section{Olgu}

Yedi yaşında erkek hasta üç gün önce başlayıp artan kapak kızarıklığı ve düşüklügü ile başvurdu. Öyküsünde bilinen herhangi bir hastalığının olmadığı öğrenildi. Oftalmolojik muayenesinde sol göz propitotik ve hiperemik görünümlü, direkt ve indirekt 1şık refleksleri normal,en iyi düzeltilmiş görme keskinliği 7/10 idi. Göz hareketlerinde içe bakışta minimal kısıtlılık izlendi (Resim 1). Sağ göz normaldi. Vital bulguları normal ve hemogramında yalnızca beyaz küre yüksekliği vardı(14000 $\left.\mathrm{mm}^{3}\right)$. Biyokimyasal değerleri ve diğer hemogram değerleri normaldi. Hastanın çekilen orbita bilgisayarlı tomografisinde etmoit sinüzitle uyumlu alanlar ve glob medial kısmında abse formasyonu izlendi (Resim 2). Etmoid sinüzite bağlı subperiostal abse düşünüldü. Hospitalize edilerek sistemik ampisilin-sulbaktam, metranidazol ve topikal moxiflaksosin tedavisi başlandı. Tedavinin 2.günde direk ve indirekt 1şık refleksi +/+, Vizyon 0.5, İçe bakış kısıtlılığı ve propitozu artmış bulundu. Kbb ile konsulte edilerek endoskopik drenaj planland1. Postoperatif birinci Günde kapaktaki propitozis ve hiperemi gerilemiş, göz hareketleri her yöne serbest ve görme keskinliği 8/10 izlendi. Bir hafta sonraki kontrolünde görme keskinliği 10/10, göz kapağı doğal ve göz hareketleri serbest izlendi (Resim 3). Cerrahi esnasında labaratuvara gönderilen drenaj materyali sinüzit lehine yorumlandı. 


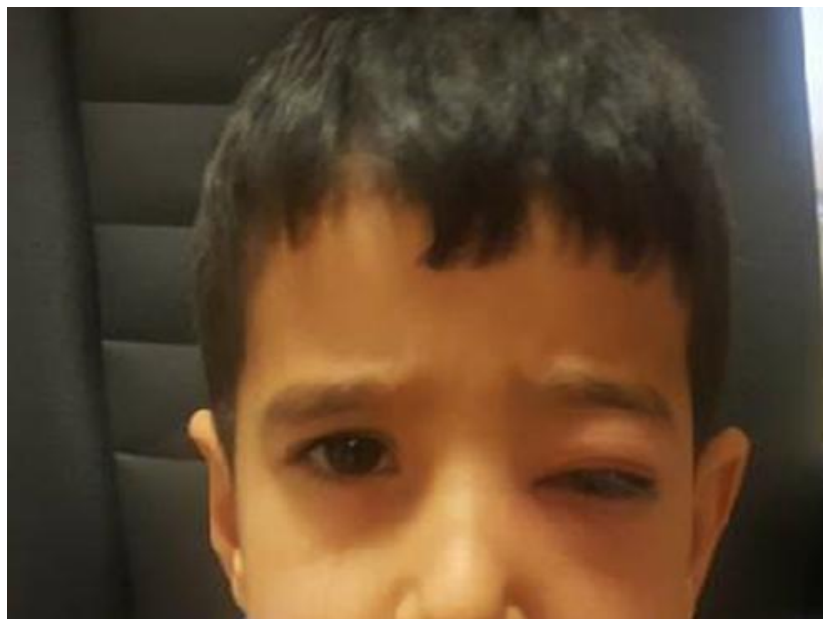

Resim 1. Olgumuzun başvurusunda sol üst göz kapağında belirgin olan şişlik ve kızarıklık.

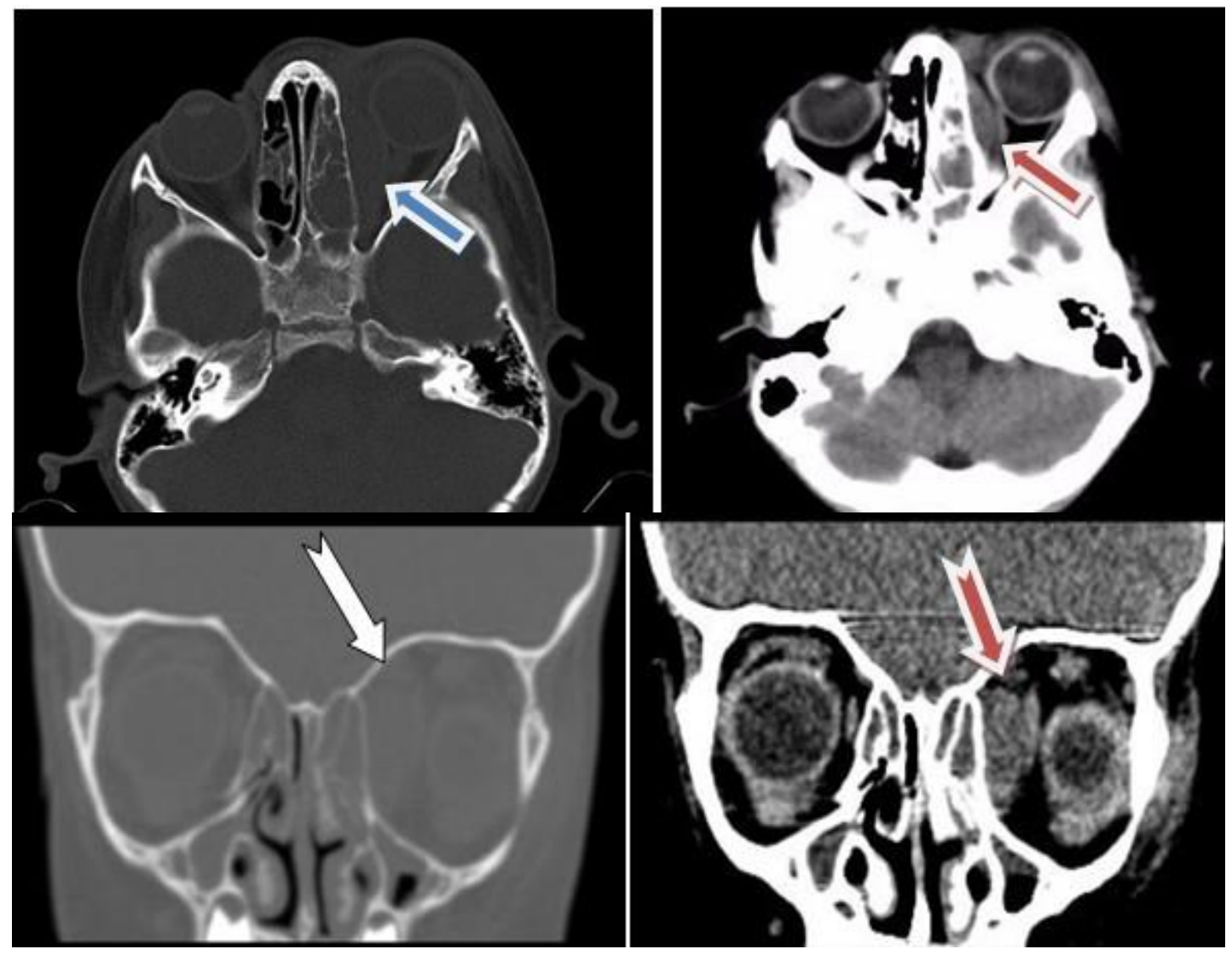

Resim 2. Aksiyel orbita bilgisayarlı tomografi incelemesinde, solda etmoidal sinüzit, maksiller sinüzit, frontal sinüzitle uyumlu alanlar ve globun anterosüperior kesiminde periferal kontrast tutulumu gösteren apse formasyonları görülüyor( $\mathrm{Sağ}$; kemik pencere. Sol; yumusak doku penceresi) 


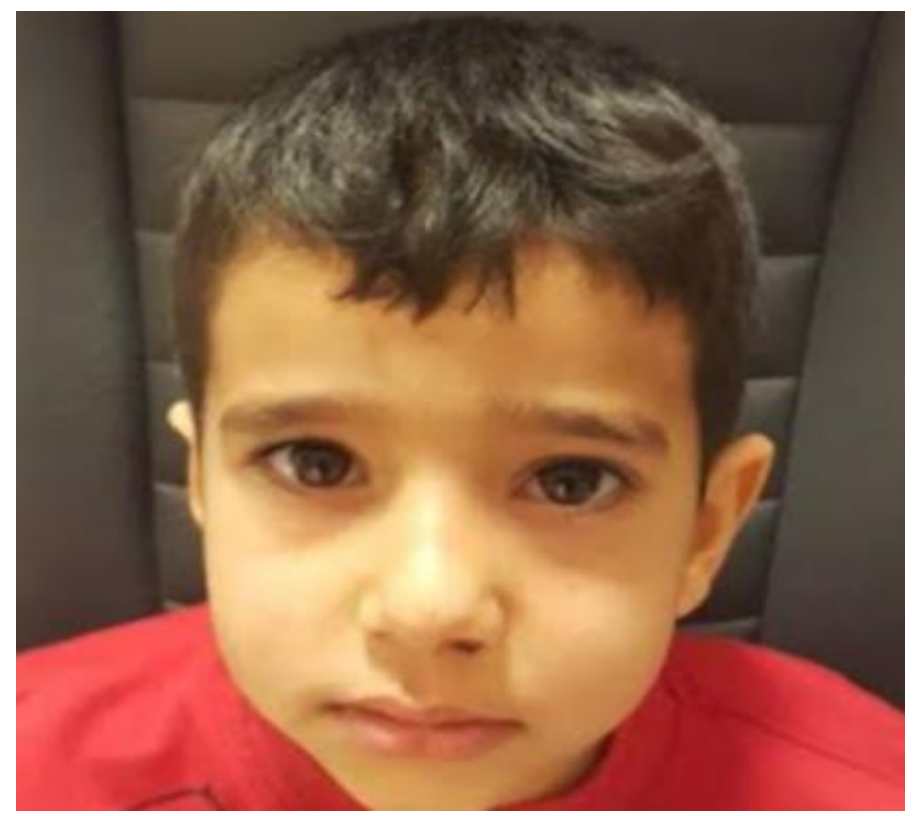

Resim 3. Olgumuzun ameliyat sonrası 10. gün sol üst göz kapağında belirgin düzelme.

\section{Tartışma}

Orbital enfeksiyonlar genellikle paranazal sinüslerden komşuluk yolu ile oluşur (3, 6,12) . Orbita ile nazal bölgeyi birbirinden ayıran lamina papyrecea oldukça ince ve vasküler bir kemik dokusudur. Bu yüzden paranazal bölgedeki enfeksiyonların agresif bir şekilde orbitaya yayılımına sebep olur $(3,6,12)$. Sinüzit çocuklardaki orbital enfeksiyonların en sık görülen sebebidir $(3,4,6)$. Bizim olgumuz da etmoid sinüzit ile ilişkilendirilen pediatrik subperiostal orbital abse idi. Subperiostal absedeki klinik bulgular propitozis kemozis ve laterale bakış dışındaki göz hareketlerindeki kısıtlılıktır (2.3.6). Olgumuzda 3 gündür olan propitozis, görme azlığ 1 ve içe bakışta kısıtlılık mevcuttu. İntraorbital apse tanısında BT hem tanının doğrulanması hem de paranazal sinüslere veya orbital ve intrakraniyal apse gibi sinüzite bağlı gelişebilecek komplikasyonların değerlendirilmesinde yararlıdır $(1,2,3,6) \mathrm{Biz}$ de olgumuzda BT çekilmesini tercih etik. Orbital selülit veya apselerin tedavisine intravenöz antibiyotik ile başlanır, 24-48 saat içerisinde düzelme görülmeyen ve progresyon gösteren 
olgularda cerrahi müdahale planlanır. Orbital selülitli hastaya acil yaklaşımda intravenöz antibiyotik tedavisi veya cerrahi tedaviden hangisinin daha yararlı olduğu tartışmalıdır $(2,3$, 6, 13). Rahbar ve arkadaşları, öncelikle intravenöz antibiyotik tedavisi ile başlayıp, 24-48 saat içerisinde eğer oftalmolojik muayenede periorbital ödemde iyileşmeme, proptozisin kötüleşmesi ve göz hareketlerindeki bakış kısıtlığının sebat etmesi veya kötüleşmesi durumunda cerrahi tedavi önermişlerdir (5). Orbital komplikasyonlardaki endoskopik cerrahinin yeri de tartışmalıdır. Endoskopik sinüs cerrahisinin son zamanlarda gelişen bir cerrahi teknik olduğunu ve orbital komplikasyonlarda nadir kullanıldığını söyleyen çalışmalar mevcuttur $(2,6)$. Biz olgumuzda başlangıç olarak konservatife tedaviyi tercih ettik. Propitoz ve göz hareketlerindeki kısıtlılık artması görme keskinliğinin azalması üzerine oluşabilecek intrakraniyal komplikasyonları da göz önünde bulundurarak hızlı bir şekilde cerrahi drenaj planladık. Endoskopik drenajın daha az agresif olacağını düşündük ve hastanın kliniğinde dramatik düzelme gözlemledik.

Olgumuzu sunarken; periorbita ve orbitanın mikrobiyal enfeksiyonları, genellikle çocuk ve genç erişkinlerde sinüzit komplikasyonu olarak karşımıza çıkabileceğini, BTnin komplikasyonların erken dönemde tanınmasına yardımcı olabileceğini hatırlatmayı planladık. IV geniş spektrumlu antibiyotik ve gerekli durumlarda drenaj hastalığın başarılı bir şekilde tedavisini sağlar. Tedavinin geç yapıldığı veya yetersiz olduğu durumlarda görmeyi veya hayatı tehdit edebilen komplikasyonlara beyin absesi, menenjit veya kavernöz sinüs trombozu neden olabilir. Bu nedenle preseptal ve orbital sellülitlerin erken tanı ve tedavisi büyük önem taşımaktadır. 


\section{Referanslar}

1. Özen M, Arslan A, Doğanay S, Güngör S. Sütçocukluğu Döneminde Seyrek Görülen Bir Orbital Apse Olgusu. İnönü Üniversitesi Tıp Fakültesi Dergisi 2006;13(2): 105-7.

2. Ulaş B, Yaycıoğlu RA, Erkan AN, Aydemir F. Subperiostal Orbital Abscess and Frontal Epidural Abscess Due to Sinusitis: A Case Report. Turk J Ophthalmol 2013; 43(6): 464-7.

3. Pjerin Radovani, Dritan Vasili, Mirela Xhelili, Julian Dervishi Orbital Complications of Sinusitis. Balkan Med J 2013; 30(2): 151-4.

4. Kinis V1, Ozbay M, Bakir S, Yorgancilar E, Gun R, Akdag M, Sahin M, Topcu I. Management of orbital complications of sinusitis in pediatric patients. J Craniofac Surg. 2013 Sep;24(5):170610 .

5. Rahbar R, Robson CD, Petersen RA, DiCanzio J, Rosbe KW, Mcgill TJ, et al. Management of orbital subperiostal abscess in children. Arc Otolaryngol Neck Surg. 2001;127(3):281-6.

6. Col S.K. Singh a, Surg Cmde E. James (Retd)bCol K. Sabarigirish Wg Cdr H. Swami a, Maj Tarun Sood c Bilateral orbital complications of paediatricrhinosinusitis. Medical Journal Armed Forces India 2014;70(1):68 -72.

7. Gallagher RM, Gross CW, Phillips CD. Suppurative intracranial complications of sinusitis. Laryngoscope. 1998;108(11):1635-42.

8. Sow AJ, Jahendran J, Toh CJ, Kew TY. Sphenoethmoid sinusitis in a child resulting in a disastrous intracranial sequela. Ear Nose Throat J. 2012;91(11):E20-2.

9. Ketenci İ, Ünlü Y, Vural A, Dogan H, Sahin MI, Tuncer E. Approaches to subperiosteal orbital abscesses. Eur Arch Otorhinolaryngol. 2013;270(4):1317-27.

10. Gardiner LJ. Complicated frontal sinusitis: evaluation and management. Otolaryngol Head Neck Surg. 1986;95(3):333-43.

11. Stankiewicz JA, Nevell DJ, Park AH. Complications of inflamatory disease of the sinuses. Otolaryngol Clin North Am. 1993;26(4):639-55.

12. Rabuzzi DD, Hengerer AS. Complications of nasal and sinus infections. In: Bluestone CD, Stool SE, editors. Pediatric Otolaryngology. Philadelphia: WB Saunders Company; 1990. pp. 745-51.

13. Ayfle Tülin Berk, Ziya Ayhan, Aylin Yaman, Cenk Ecevit Diagnosis and reatment of Preseptal Cellulitis in the Pediatric age Group. Turk J Ophthalmol.2010;40(4)227-31. 